\title{
Wolff-Parkinson-White syndrome: inadvertent permanent ablation of the accessory pathway during electrophysiological study
}

\author{
KILLIAN ROBINSON, EDWARD ROWLAND, * DENNIS M KRIKLER \\ From the Division of Cardiovascular Disease, Royal Postgraduate Medical School, Hammersmith Hospital, \\ London
}

SUMMARY A case of permanent unintentional ablation of an accessory pathway during electrophysiological study is reported. Possible factors predisposing to such ablation include the location and depth below the endocardium of the accessory pathway.

Ablation of the accessory pathway is an established form of treatment in patients with the pre-excitation syndrome. ${ }^{1}$ Conventionally, this is performed at operation but it has more recently been achieved by techniques that use transvenous wires.

Unintentional ablation of the accessory pathway may follow His bundle ablation ${ }^{2}$ and may also be a transient phenomenon during electrophysiological study. ${ }^{3}$ We report a case of permanent ablation of the accessory pathway that followed the introduction of a recording wire into the coronary sinus.

\section{Case report}

An 18 year old man was referred for evaluation of a narrow complex tachycardia that had been refractory to medical treatment. He had initially presented at the age of 12 days with congestive heart failure secondary to paroxysmal tachycardia. He remained symptom free on digoxin until the age of 16 years when tachycardia recurred. Despite treatment with various medications the arrhythmia persisted and he was admitted for electrophysiological study.

Physical examination was normal. Although pre-excitation was absent at times, 12 lead electrocardiograms usually showed the Wolff-ParkinsonWhite pattern type B (fig 1). At the beginning of electrophysiological study the pre-excitation was apparent but after the placement of the transvenous

Requests for reprints to Dr Dennis M Krikler, Division of Cardiovascular Disease, Royal Postgraduate Medical School, Hammersmith Hospital, Ducane Road, London W12 0HS.

^Present address: National Heart Hospital, Westmoreland Street, London WIM 8BA. electrodes delta waves were no longer seen.

Despite pacing from multiple sites no evidence could be found of anterograde or retrograde conduction across an accessory pathway and reentrant arrhythmia could not be induced. Limited electrophysiological studies were repeated on two subsequent occasions and again failed to show any evidence of pre-excitation or tachycardia. Since the initial electrophysiological study five years ago the patient (now 23 years old) has had no tachycardia and no subsequent electrocardiograms have shown evidence of the Wolff-Parkinson-White syndrome (fig 2).

\section{Discussion}

Interruption of the accessory pathway either surgically $^{45}$ or by trañsvenous wires ${ }^{1}$ is now an

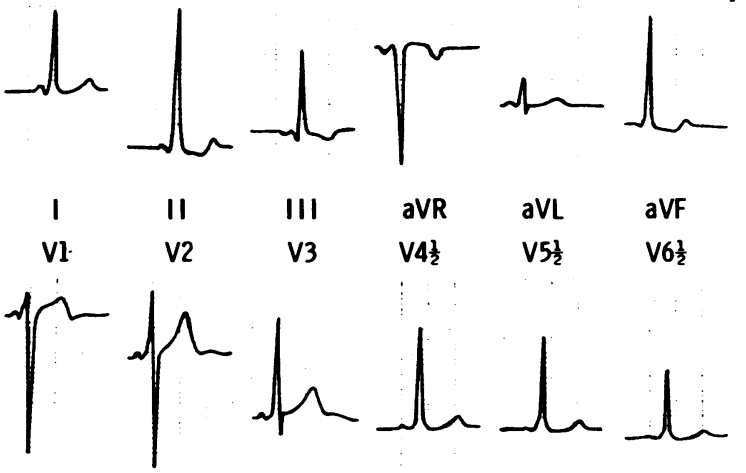

Fig 1 Twelve lead electrocardiogram recorded before electrophysiological study and showing

Wolf-Parkinson-White syndrome type B. 


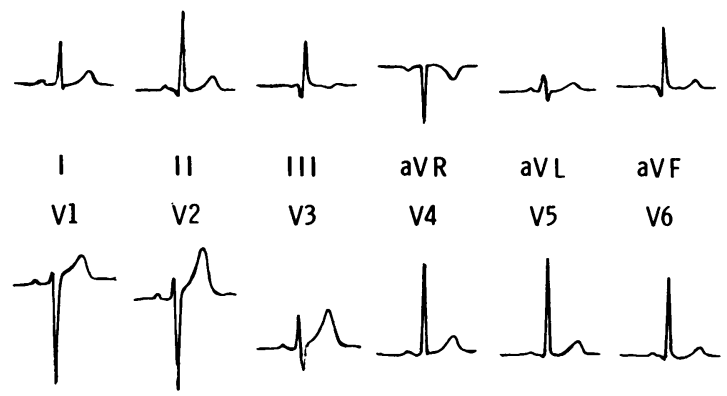

Fig 2 Twelve lead electrocardiogram recorded after electrophysiological study. The pattern of pre-excitation has disappeared.

established treatment in the Wolff-Parkinson-White syndrome. Though transient disturbances of accessory pathway function have been reported, ${ }^{3}$ we are unaware of permanent destruction of a bypass tract during electrophysiological study produced by manipulation of the wire alone.

Interruption of conduction by an accessory pathway in this manner will depend on several factors, including the site of the accessory pathway, its dimensions, and its depth below the endocardium, as well as the vigour with which the wire is being manipulated. The ease with which destruction occurred in this case, with gentle movement of the wire, suggests that the site or depth below the endocardium or both may have rendered the pathway susceptible to minor trauma. We cannot distinguish whether the pathway was in the mouth of the coronary sinus or just beneath the endocardium, over the atrioventricular node itself.

Although there are some reports that deal with the size of bypass tracts, ${ }^{67}$ the depth of accessory pathways below the endocardium has received scant attention, though Lev et al reported a right-sided subendocardial accessory pathway ${ }^{8}$ and this has been considered important in determining the type of surgical approach. ${ }^{9}$

The depth below the endocardium of these pathways may also determine their susceptibility to attempts at intracardiac electrical ablation; this may explain the relative ease with which some ablations 
are performed while others prove difficult. Furthermore, vascular anomalies of the coronary sinus may also be associated with Wolff-Parkinson-White syndromes and possible transvenous destruction of these might also have accounted for the disappearance of pre-excitation. ${ }^{9}$

\section{References}

1 Fisher HD, Brodman R, Kim SG, et al. Attempted non-surgical electrical ablation of accessory pathways via the coronary sinus in the Wolff-Parkinson-White syndrome. J Am Coll Cardiol 1984;4:685-94.

2 Gallagher JJ, Svenson RH, Kasell JH, et al. Catheter technique for closed chest ablation of the atrioventricular conduction system. A therapeutic alternative for the treatment of refractory supraventricular tachycardia. $N$ Engl J Med 1982;306: 194-200.

3 Novick TL, Pritchett ELC, Campbell RWF, Rogers GC, Wallace AG, Gallagher JJ. Temporary, catheter-induced block in accessory pathways. Circulation 1978;58:932-40.

4 Sealy WC, Gallagher JJ, Wallace AG. The surgical treatment of Wolff-Parkinson-White syndrome. Evolution of improved methods for identification and interruption of the Kent bundle. Ann Thorac Surg 1976;5:443-57.

5 Gallagher JJ, Sealy WC, Anderson RW, et al. Cryosurgical ablation of accessory atrioventricular connections. A method for correction of the preexcitation syndrome. Circulation 1977;55:471-9.

6 Verduyn Lunel AA. Significance of annulus fibrosus of heart in relation to AV conduction and ventricular activation in cases of Wolff-Parkinson-White syndrome. $\mathrm{Br}$ Heart $J$ 1972;34:1263-71.

7 Brechenmacher C, Laham J, Iris L, Gerbaux A, Lenegre J. Etude histologique des voies anomales de conduction dans un syndrome de WolffParkinson-White et dans un syndrome de LownGanong-Levine. Arch Mal Coeur 1974;67:507-19.

8 Lev M, Sodi-Pallares D, Friedland C. A histopathological study of the atrioventricular communications in a case of WPW with incomplete left bundle branch block. Am Heart J 1963;66:399-404.

9 Guiraudon GM, Klein GJ, Sharma AD, Milstein S, McLellan D. Closed-heart technique for Wolff-Parkinson-White syndrome: further experience and potential limitations. Ann Thorac Surg 1986;42:651-7. 